\title{
Creative Interventions: Integrating Arts-Based Approaches in a University Access Programme
}

\author{
Amalia Beagle \\ https://orcid.org/0000-0002-1822-0568 \\ University of Johannesburg, South Africa \\ amalia@beagle.org.za
}

\section{Abstract}

This article is based on my master's degree study at the University of Johannesburg that evaluates the impact of utilising arts-based approaches in the Workplace Preparation (WPP) module curriculum. The study demonstrates that when integrated into teaching and learning, arts-based approaches expand the capability of the curriculum to achieve more equitable and accessible participation. I use an action research approach in the study to investigate how creativity and arts-based practices might instil experiences of empowerment and agency in students in the classroom. I draw from literature to gain multiple critical perspectives in order to frame and demonstrate arts-based approaches to teaching and learning that embrace alternative ways of knowing, communicating and interacting. The findings suggest that culturally relevant arts-based approaches play a legitimate and vital role in expanding the pedagogic space in order to foster embodied learning opportunities that acknowledge and include non-linear, somatic, visceral, emotional and symbolic dimensions. Arts-based methods advance transformative agendas and support learning in the current higher education (extended programme) context. The study involves an actionable intervention that uses arts-based methods to present the Workplace Preparation module. Arts-based activities and lesson plans are devised for integration into the existing formal programme and can be used and adapted as a resource for lecturers in the Workplace Preparation Department.

Keywords: arts-based; culturally relevant education; multimodality; extended curriculum; critical pedagogy; capabilities

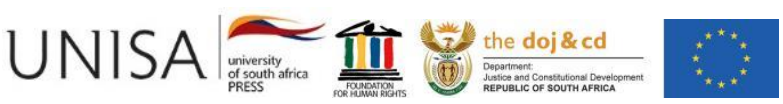

Education as Change 


\section{Introduction}

This article explores how arts-based pedagogic approaches expand opportunities for inclusion and participation in the extended programme Workplace Preparation (WPP) classroom. It will give an account of the master's degree study I conducted integrating arts-based approaches that focus on creative interventions in teaching and learning into the extended curriculum Workplace Preparation (WPP) module.

To begin, I provide a background to the study, which is conducted within the contemporary higher education context in South Africa. This is followed by a discussion of challenges to access specific to extended curriculum programme (ECP) and at-risk students. Thereafter the study is located in a theoretical framework that seeks to address the aforementioned challenges and proposes an arts-based pedagogical methodology to promote inclusive curricula.

The objectives of this master's degree study were, first, to understand how arts-based methodologies, such as culturally relevant arts education (CRAE) (Stone Hanley et al. 2013), could be operationalised in the WPP classroom to promote a more democratic, affirming and relevant learning environment in which diverse students can engage and actively contribute to the collective knowledge shared in the learning environment. A second objective was to consider and apply the concepts and discourse of agency and empowerment through the framework of transformational theory (Freire 2005). The final objective was to analyse student experiences and feedback from the classes that are exposed to arts-based methods with the aim of developing an understanding of how the methods serve to expand opportunities for inclusion and participation in the classroom.

I draw from my own background in arts and education to adapt and design arts-based interventions in the WPP curriculum. The introduction of arts-based methods in the classroom enabled a shifting of traditional educational power relations in order to establish safer spaces in which learning occurs and foster opportunities for greater cocreation of knowledge in the classroom. The arts-based interventions encourage a more invested and engaged participation in the learning process and promote engagement with content so as to build capacities for agency and volitional learning. I found that creative opportunities in the classroom enable the voice and participation of the heterogeneous student cohort.

\section{Access}

Universities all over the world, and especially in South Africa, are grappling with "envisioning" the University of the twenty-first century (Walker 2005, 4). Cheryl Hendricks and Brenda Leibowitz (2016) identify the important role and purpose of universities in thinking through broader societal issues, and they argue for a focus on pedagogy as a vital aspect of this dialogue. 
Yet Hendricks and Leibowitz (2016) note that rapidly increasing student numbers and the diversification of the student body have not been accompanied by equal increases in levels of student success (Van Zyl and De Kadt 2011, 1). Reflecting a shifting narrative from "under-prepared students" to "under-prepared institutions" (Manik 2015, 226), Hendricks and Leibowitz (2016) argue for the need to provide students with "access to alternative ways of envisioning the world and interpreting their experiences". This line of thinking has nudged contemporary paradigms towards a renewed focus on pedagogy, with implications recognising that subjective emancipation is an essential component of transformational education.

Wally Morrow (2007) and Heila Lotz-Sisitka (2009, 15) argue that effective transformation of the university learning environment cannot be achieved by focusing solely on formal access, but that concern for epistemological access is necessary too. Hendricks and Leibowitz (2016), Bozalek, Garraway and McKenna (2011), Du Plooy and Zilindile (2014), and Rusznyak et al. (2017) draw attention to the role of pedagogy by expanding the idea of epistemological access to shift the focus from institutional access to pedagogical access. These shifts aim to effect a meaningful and expanded understanding of what constitutes access for incoming students.

Increasingly educators are encouraged to construct curricula that are "ever respectful of the irreducible plurality of opinion" (Ballim 2018, 143) and that expose students to "as many ways of knowing as possible" $(2018,136)$.

\section{Melanie Walker argues for an}

alliance of the capability approach developed by Amartya Sen with ideas from critical pedagogy for undergraduate university education which develops student agency and well-being on the one hand, and social change towards greater justice on the other. (Walker 2010, 889)

The capability approach, as defined by Walker, is an instructive source for this study as it foregrounds the "basic heterogeneity of human beings as a fundamental aspect of educational equality" (Walker 2010,9), and it identifies agency and empowerment as essential components of transformational pedagogy (Calitz 2015; Walker 2005, 2010). Calitz recentres the classroom as an opportunity to "create conditions that can enable participation and feelings of belonging" $(2015,192)$.

\section{Students "at Risk"}

The first year of university is identified as a critical year because students adapt to the new demands and rigours of higher education. It is a transitional year in which students grapple with a multitude of new challenges. Students need to adapt both academically and socially. These challenges are exacerbated by, sometimes extreme, financial constraints (Bawa 2014, v-vii; Bozalek, Garraway and McKenna 2011, 2; Manik 2015, 233-34; Van Zyl 2013, 1). Students in the extended programmes are considered at 
greater risk due to the "articulation gap" (CHE 2015, 2). ${ }^{1}$ Many learners are from disadvantaged social and educational backgrounds and find it especially challenging to adapt to the new environment (Shandler 2014, 1533). ${ }^{2}$

\section{The Heterogeneous Classroom: Personal Perspective and Observations}

This research study is located in the WPP module of the Extended Curriculum Access Programme where I have been an educator since 2009.

In my experience, the average extended curriculum student cohort varies only slightly across the different faculties and different campuses where I teach. The gender and "race" distributions are mostly representative of South African demographics, and a percentage of international students (more so in the engineering departments), LGBTQ+, minority "races", religions and other minority groups are all represented in the room. Mixed into this diverse cohort are students from both urban and rural backgrounds. Given that English is the medium of instruction, most students are learning in their third or fourth language. In this multilingual learning environment, in addition to understanding the content being taught, many of the students also struggle with understanding one another. While the majority of students are aged between 19 and 25 years, there are typically a number of mature students in the classes too. The classroom reflects the "heterogeneous"3 nature of many contemporary South African classrooms. The University of Johannesburg (UJ) attracts students from all over South Africa as well as many international students. Many of the students are far from home. They have not yet established personal bonds and support structures. They are adapting to new social, language and cultural norms. This transition can be frightening and lonely for many.

The Workplace Preparation (WPP) classroom constitutes a diverse setting with students experiencing many new challenges. The WPP module has a strong socio-emotional component that seeks to support students through the transitions they face in their first year of higher education.

1 An "articulation gap" refers to the disparity between the learning requirements of higher education programmes and the knowledge and competencies of students entering university. For more information on the policy environment that governs foundation provision, see the Department of Higher Education and Training's White Paper for Post-School Education and Training: Building an Expanded, Effective and Integrated Post-School System (DHET 2013) and the Ministry of Education's National Plan for Higher Education (MoE 2001).

2 Colette February (2016, iii) points out that, especially in South Africa, the "non-traditional" student is under-researched and insufficiently articulated and warns that the term "non-traditional" does little to recognise and respond to a blended understanding of student identities/constructs and their corresponding needs.

3 February argues for the reimaging of the constructs of student identity, especially from that of a deficit model to one that recognises and embraces the multitude of nuances of the "non-traditional" learner (February 2016, 75). 


\section{The Extended Curriculum Workplace Preparation Module}

Workplace Preparation is a foundational module offered in the extended curriculum. It is a continuous assessment soft skills module that is credit bearing. All registered extended curriculum students from each faculty are required to pass this module. Students registered for this module attend five lecture sessions per week throughout the academic year.

The units covered in the syllabus are designed to teach students practical life skills (such as time management and study skills) as well as to address the psycho-social aspects of soft skills (such as values, emotional intelligence, stress management, leadership and team dynamics) and require personal introspection and critical reflection.

While the aim in the delivery of the WPP module is to create a relatively informal learning environment that is based on discussion and personal reflection, the modality in the classroom essentially remains traditional and transmittal, and formal learning is delivered through a passive and hierarchical structure and form. While this might be an efficient way to seat increasingly large student numbers in a lecture hall, I have found that few students excel in this environment. This "sage on the stage" format forces students into rigid sitting postures that restrict interactions to listening, reading/writing, and verbal discussions. Student feedback reveals that they find it hard to concentrate in these environments.

The traditional pedagogic space is "alienating" (Calitz 2015, 162, 171; Mann 2008, 58) and designed to reinforce the hegemonic power relations that place the learner in a passive position, thereby replicating unequal power relations through their insistence on hierarchical knowledge generation and transfer (Freire 2005, 71; Mann 2008, 6; McMahon and Portelli 2014, 6). In this context, educators are positioned as intimidating and powerful agents that students find particularly difficult to challenge or contradict (Mann 2008, 13). Traditional teaching practices cause learners to doubt the value of their contributions in the classroom and therefore restrict participation.

This traditional approach to pedagogy also does not take into account the diversity of learning styles ${ }^{5}$ and needs of the student cohort. Consequently, it disempowers students and does not engender experiences of ownership of learning or provide opportunities to develop personal strengths (Mann 2008, 129). These challenges constitute some of the barriers to access experienced in the room.

4 "Sage on the stage" is a phrase that refers to a traditional, transmittal teaching approach and is in contrast to the more contemporary, constructivist teaching approaches that recognise the learner as having existing knowledge and prior learning that can be engaged in active learning (King 1993, 30).

5 Learning styles refer to a range of competing and contested theories that aim to account for an individual's learning and posit that people can be classified by their style of learning. These classifications include kinaesthetic, aural and visual sensory modalities (among others). 


\section{Literature}

In presenting an argument for introducing arts-based methods into the WPP curriculum, I draw from relevant arts-based approaches and pedagogical strategies to motivate and inform my teaching practice. I use this framework to understand how creativity and the arts become significant agents of change in the classroom through the adoption of culturally relevant arts education (Stone Hanley et al. 2013) as a pedagogical model.

In addition, I refer to transformational theories and critical pedagogy (Freire 2000, 2005; Sen 2005) as the ideological bedrock of my work. I explore notions of disrupting traditional power relationships in pedagogical practices and propose the introduction of arts-based interventions to the curriculum to facilitate greater inclusion, participation and representation for all the students in the classroom.

This study takes a social emancipatory view of transformational pedagogy and draws on Paulo Freire's $(2000,2005)$ notions of embodied learning, curiosity, horizontal leadership and the co-creation of knowledge. I assess the applicability of this in enabling agency and empowerment through enhancing opportunities for voice and visibility, volition and empathy in the classroom.

Capacities for voice, volition and empathy constitute important and recurring aggregations of empowerment and agency in the discourse (Calitz 2015; Walker 2005, 2010; Walker and Unterhalter 2007) and are identified for this study as key measures for increased student agency in the classroom.

Critical transformative theory breaks the mould and is counter-hegemonic in that it disrupts dominant and normative educational practices that are oppressive and alienating (Freire 2005, 70). Its application recommends a shift in the power relations between teacher and student towards installing a more egalitarian and democratic value system in which participants are represented in and empowered to contribute to the interpretation and generation of knowledge.

\section{Arts-Based Approaches}

Practices dedicated to developing more flexible, inclusive and participatory classrooms that are responsive to the reality of the multi-diverse learning environment have shown how arts-based methods facilitate learning.

The term multimodal ${ }^{6}$ pedagogies signals a paradigm shift in relation to forms of representation and meaning-making in classrooms. In broad terms, it

reconceptualises communication in the contemporary classroom beyond the linguistic, locating language as one mode of communication amongst multiple semiotic modes, all

6 The term multimodal learning is increasingly associated with developments in electronic learning platforms. 
of which function to communicate meanings in an integrated, multi-layered way. (Stein and Newfield 2007, 920)

The utilisation of arts-based approaches in multi-literate contexts has been explored extensively by David Andrew (2011, 2014), Arlene Archer (2014), Pippa Stein and Denise Newfield (2007) and Gunther Kress, Jon Ogborn, Carey Jewitt and Charalampos Tsatsarelis (2001). Multimodality is credited with expanding the resources available in the classroom for communication and articulation of complex ideas. A strong argument is made by Stein and Newfield $(2007,919)$ for a classroom constituted in multimodality where arts-based methods provide alternative resources for expanding linguistic modes.

These studies conducted in contemporary South African classrooms point to the valuable contribution arts can make to curricula (Andrew 2014, 2011; Berman 2014; Liamputtong and Rumbold 2008; Newfield 2011; Stein and Newfield 2007). This study seeks to contribute to the growing body of evidence of the efficacy of arts-based pedagogic approaches in supporting transformation, particularly in the Workplace Preparation module of the extended curriculum programme.

Newfield (2011), Stein and Newfield (2007), Andrew (2011, 2014), Archer (2014) and others have shown how diverse "classrooms become more participatory, agentive spaces" where learners can be productive and expressive (Stein and Newfield 2007, 919). Multimodal approaches offer a means to work against learner-deficit models.

No longer constrained by the limited forms of the past, these methods can promote inclusive and rich ways to "access experiential knowing" (Liamputtong and Rumbold 2008, 1). Arts-based methods are credited with deepening learning by providing opportunities for visceral, emotive and embodied experiences that enhance cognition. Learning with the whole body provides a more holistic view of learning that embraces a variety of modes of making meaning and representing knowledge (Andrew 2011, 2014; Berman 2018; Berman and Netshia 2018; Bozalek, Garraway, and McKenna 2011; Eisner 2002; Liamputtong and Rumbold 2008; Newfield 2011). In their multiple configurations, such pedagogies have the power to "unleash creativity, intelligence, and agency through the creation of symbolic identity objects and practices that lead to creative rapprochements" (Stein and Newfield 2007, 919).

As a form of education, the traditional lecture, with the lecturer on a podium, leads only to mechanical memorisation. Recent studies (Rusznyak et al. 2017, 208) conducted with first-year university students in South Africa have shown that after a traditional lecture most students were only able to recognise the content taught, but were unable to articulate these concepts. They argue that students need dedicated time and space in the curriculum to process content: they need to spend time in a process of "distanciation" (Ruznyak et al. 2017, 209) to be able to articulate their understandings.

Arts-based methods can provide the space in which these deep cognitive processes can occur. Bozalek, Garraway and McKenna $(2011,3)$ support the call for dedicated time 
and activities in a curriculum that can accommodate this process of cognition and "allow for connections and relations to become apparent". One of the findings in this study revealed that introducing arts-based activities at relevant points in the WPP curriculum can allow students the time and tools needed to unpack the theory offered in the units.

\section{Culturally Relevant Arts Education-CRAE}

Integrated arts-based methods, underpinned by the concepts of culturally relevant arts education, provided a useful model with which to respond to and accommodate the diversity in the classroom. Culturally relevant education is founded on a conceptual framework that argues all aspects of teaching and learning must involve students' cultural backgrounds, interests and lived experiences. Increasingly, meaningful and relevant education is viewed as instrumental in improving student engagement and achievement.

CRAE (Stone Hanley 2013) is a pedagogy that is best suited to a multicultural, critical, contextual teaching and learning paradigm. It is not prescriptive. Instead, it offers guiding principles with which to navigate a contemporary classroom. Originally emerging from American contexts and largely concerned with minority challenges, it nevertheless provides a philosophical framework that recognises the struggle for equitable learning that promotes affirmation of diversity. It is pertinent in the South African higher education context because universities are currently engaged in a process of democratisation to reflect the country's constitutional and social justice aims.

CRAE is a pedagogic model that is anchored in the use of the imagination. Creativity is valued for its inherent ability to empower students by instilling a sense of agency and also for its power to foster (generative) imagination as a means to "construct visions of self-determination" (Stone Hanley 2013, 2). Furthermore, according to Stone Hanley $(2013,7)$, the integration of creativity and arts production in contextual teaching and learning, within a multicultural and critical pedagogic paradigm, builds positive identity development and intrinsic motivation and ownership.

\section{Research Design}

\section{Project Planning, Implementation and Observation}

For the study, I used an action research (AR) approach to record and reflect on the implementation of culturally relevant arts education in my teaching of the Workplace Preparation (WPP) module. This action project embraced arts-based methods: first, as applied and integrated in pedagogical practice as a means of enquiry in classroom teaching and learning, and second, as a research tool to generate, collect and interpret data.

AR is a form of enquiry that is intended to have "both action and research outcomes" and is focused on achieving a real improvement or change in the context of practice (Gravett 2002, 2). It is also an "iterative process which converges towards a better 
understanding of what happens" (Patton 2011, 280). I keenly observed and reflected on the different aspects of the intervention, constructing ongoing formative evaluations through the cycles to help formulate a holistic picture of the project. As a practising educator, I am offered a broad methodological framework via AR that compels me to critically reflect on and improve my own pedagogical practice on a continual basis.

The AR project, implemented in three cycles from 2017-2019, enabled me to identify challenges experienced in my practice and initiate a change to address these concerns. I observed and reflected on the impact the intervention had in my classroom so as to gain knowledge and insights in order to continuously improve my practice. I used a range of qualitative tools to interpret and evaluate the impact of the intervention. The study utilised analysis methods from development arts and from educational fields. This reflects the objectives of this study, which conceptualised the integration of creativity in educational practice by embracing methods that bridge the boundaries between these fields and introduce creative methodologies to expand the educational space in order to include alternative ways of knowing.

\section{Consent and Ethical Considerations}

Ethical clearance for the study was granted by the Faculty of Education Research Committee. I have included some of the participants' feedback to amplify their role and contribution in reaching these findings. Participants consented to the use of their artworks and statements; however, all personal information remains anonymous to protect and maintain confidentiality.

\section{Documenting the Intervention}

I drew from a variety of data sources throughout the project, thereby resulting in a multilayered data set, which includes photograph and video recordings taken with my cell phone during classes, focus group interviews, photographs of artworks produced by students, my own journal entries, and both WhatsApp texts and paper-based student feedback solicited after arts-based lessons. The data was generated and collected over the first two project cycles in 2017 and 2018.

\section{Focus Group}

Volunteer-based focus group interviews were conducted with participants in each cycle of the study at the end of each academic year. In the first project cycle, the group interviews were conducted as informal discussions. The interviews were audio-recorded and transcribed for accuracy. For the second project cycle, the focus group participants completed a paper-based questionnaire. The issues that were identified in the first cycle were clarified and verified in the 2018 cycle of the project. 


\section{Limitations}

Quantitative analysis was not a component of the study. While I have not quantified the subsequent achievements from the students participating in this study, anecdotal and qualitative evidence indicated improved end-of-year results.

\section{Analysing and Interpreting the Data}

I applied a variety of qualitative tools to examine and interpret the data. These qualitative methods of interpretation provided a textually nuanced analysis of the data set and helped me to identify important and/or sensitive aspects of the evidence and to articulate some of the hard-to-pin-down qualities of the data.

A visual analysis of the data revealed many interesting and rich observations, indicating positive responses. The approach was considered affirming as it included elements of play, creativity, and a departure from the orthodox hierarchical power structure of the classroom.

I used selected community development tools, such as principles of participatory research and most significant change (Davies 1998), to evaluate change and to identify sensitive issues. Through this ground-up approach, I identified key themes that were further conceptualised through a detailed grounded theory (GT) coding analysis of the focused feedback. These processes led to the distillation of the data into three discrete but interacting themes, which I present as the findings of the study.

\section{Most Significant Change}

I employed a technique often used in monitoring and evaluation in community development settings to clarify the challenges that initiated the intervention and to observe, reflect on and evaluate the efficacy of the intervention. The most significant change (MSC) technique was invented by Rick Davies as a tool used to gather, from the participants' perspectives, data on the impact and outcomes that can be used to assess the performance of a programme (Davies and Dart 2005, 72). I used participants' most significant change statements to inform the descriptions and categories for the grounded theory codes when analysing the data.

\section{The Analytical Methods of Grounded Theory}

Grounded theory was used as an analytical procedure to guide my analysis of the data I collected. Kathy Charmaz (2006) identifies two distinct coding phases. In the "initial phase", the researcher breaks up dense data into a manageable form. This leads to a "focused phase" that is more selective and looks for salient categories and their relationships (Charmaz 2006, 46). This process involves using multiple stages of data collection and the refinement of categories of information, as well as determining their interrelationships. In this regard, grounded theory served as a method of data analysis in which coding was used as a strategy to unpack and understand data in order to 
generate interpretations based on themes that emerged from the data. GT was employed in this study not to develop a robust theory grounded in data, but rather to present a rigorous and exhaustive analysis that is systematic and rooted in the data.

The GT approach to analysis was used to verify and triangulate interpretive findings. GT offered a procedural pathway for analysis through the systematic collection, organisation, and detailed analysis of a variety of data. This made it possible to conduct systematic checks during both the collection and analysis of the data, thus presenting a dependable and accurate method of analysis.

\section{The Action Research Project}

\section{Integrating Culturally Relevant Arts-Based Methods in the WPP Classroom}

I adapted the principles of cultural relevance to suit my context by interpreting the notion of "culturally relevant" to reflect a contemporary, intersecting view of identity in which "culture" and "identity" are fluid and dynamic and can only be subjectively identified and expressed. Broadly speaking, "intersecting identities" refer to the idea that a single person can be at "the intersection of multiple different social identities" (Crenshaw 1994, 95). Identity, like culture, is made up of a multitude of factors and an individual is both "subject to their circumstances" and an agent able to influence which parts of themselves they present to the world (YW Boston 2017). Agency and choice in self-representation and equality as a right are fundamental to this interpretation. These concepts inform the idea that "cultural" is not about defining "culture", but more about facilitating a space in which all the participants feel safe, accepted, respected, acknowledged, valued and enabled to self-identify and to articulate this in ways that are of their own choosing. This stance recognises the plurality of the classroom and enables the expression and representation of multiple perspectives.

In my study, and in my own practice as an educator in the WPP extended programme module, I use the agentive qualities of art-making in the classroom. I do not set out to teach art, nor the skills associated with art-making. Instead, I value the essential expressive physicality of art materials and the mediating force of the artwork. I draw on the embodied benefits of art-making and the utility of the resultant artwork. The artbased activities and visual methods used in the intervention derive their inspiration from the fields of costume, fashion and jewellery design, visual arts, drama, and dance.

\section{Arts-Based Interventions}

Six arts-based lessons were developed for the WPP programme and implemented over the 2017 and 2018 cycles of the project. These activities were designed to dovetail specific units and were intended to show students the multilayered and interconnected nature of the concepts presented through the syllabus. The activities were intended to provide a time and space for students to "dwell", that is, unpack, explore, consider, think about, and reflect on the topics in the unit. I focused on non-prescriptive themes such as body adornment (Figure 4) or free-standing sculptures (Figure 3) to enable students to 
exercise their creative agency to make art objects that reflected their unique and individual interpretations and perspectives about the topics in ways that were indirect and less threatening.

While some lessons aimed to contribute directly to the student's ability to complete the written self-reflective assessment exercises in a more considered and authentic way, other lessons focused on building relationships as opposed to formal assessment outcomes. The art activities set out to do the following: to make lessons more inspiring and relevant for the students in the room, to facilitate time and resources in order to allow for considering and reflecting on learning, and to provide indirect ways to participate in the classroom in order to build self-esteem and confidence and support positive social relationships.

I followed a similar format for each of the arts-based lessons. I begin by using arts-based methods such as storytelling, movement meditations or music to introduce the concepts or topics that we are addressing. Thereafter, I invite students to explore their ideas about the topic through their engagements with materials. Time was allocated to art-making, which was done either individually or collaboratively. The lesson activities were intentionally open ended enough for individuals in the class to enjoy complete autonomy in choosing how to interpret the topic or how to use the materials to articulate or express their ideas. The artwork was not prescriptive, and I did not provide visual examples. I motivated these briefs using words such as "consider" and "think about". Each lesson had a series of scaffolding parts that provided time, space, and materials to reflect on and interpret ideas and to visualise and communicate these ideas. I ensured that my art activity lessons were structured to include time for action and reflection. Time was allocated towards the end of each lesson (as well as at pause points throughout the activities) to share ideas and reflect on the outcomes of the lesson through group discussions.

\section{Art Materials and Processes}

I value the generative and expressive potential of art materials and non-verbal communication. Art materials provide the raw elements with which to express and communicate in non-verbal and indirect ways (see Figure 1).

Using a range of materials and processes in the classroom did not require specialised art supplies. I developed a basic art kit that included familiar art materials, such as paint, crayons, and glue, that are not specialised and not intimidating for students. For the most part, the materials used in the study were made up of collected found objects and recycled waste materials representing a range of colours, shapes, and textures. Materials and processes were introduced for their expressive potential and possibilities for metaphoric interpretation or re-interpretation as students create and attach personal meaning to their images. I also brought specific materials, such as balloons or rolls of large paper, based on the requirements of each activity and also for their expressive potential. 
When I use arts-based methods in my classroom, I become less of a lecturer and more of a facilitator. I am concerned with creating an environment in which students feel safe to explore and express their own ideas. I facilitate the "container", which is a concept used in therapeutic fields to denote both attitudes and behaviours that promote a safe and structured context (Rabiger 1990, 23).

I am always mindful of how the expressive nature of art materials and art processes possesses the ability to activate emotional responses. The emotional affects that arts practice can activate are important attributes of this model and contribute to embodied learning. As a soft skills programme, WPP is concerned with promoting self-care and lecturers are attuned to identifying and supporting at-risk students. I routinely reminded students of and referred them to the Centre for Psychological Services and Career Development (PsyCad) and other support services on campus. In my practice I continually draw on my training in counselling in developing and modelling a nonjudgmental attitude and a caring and responsive mindset to promote a safe space in the classroom.

\section{Findings}

The objectives of the series of learning action interventions in my study framed my interpretation of the data. I examine the impact of the intervention against the challenges that gave impetus to the study by asking questions around how the creative interventions impacted the relationships in the pedagogic space, as well as questions regarding how the methods impacted student capacities such as voice, volition and empathy in the classroom.

My interpretation of the findings reflects how making art was a significant agent of change in the WPP curriculum. These methods promoted pedagogic arrangements in class that dislodged the traditional power structures and enabled more democratic and supportive social relations. The methods also promoted learning abilities such as concentration, understanding and memory. Arts-based methods recognise and acknowledge students' resources and agency and help to build capacities that contribute to overcoming many of the challenges identified at the beginning of the study.

Freire $(2000,2005)$ rejects the autocratic nature of the traditional educational paradigm. This autocratic style of teaching and learning is increasingly untenable and out of sync with current pedagogical approaches. First-year students in particular feel intimidated and anxious in these environments. Anxiety creates a barrier to learning. It stultifies curiosity, which limits participation and forces learners to pursue marks rather than knowledge (Mann 2008, 129; Sen 2005, 12). Participants in this study reported how the arts-based class activities alleviated their fears and anxiety and made the learning more accessible and welcoming. A participant observed,

At first thought it was silly but then I saw everyone was smiling so I tried it and really enjoyed it. 
Culturally relevant arts-based methods enabled a re-imagining of the roles of both the teacher and the learner by bringing them closer and dislodging the levels of power dynamics between them. These methods promoted affiliations between students and lecturers as well as between peers. My own practice as an educator has been enhanced through the inclusion of arts-based methods in the classroom. This is confirmed by a participant, who said:

It was fun, it was not in an environment that was tense or negotiated.

The approach encouraged students who were previously perceived as reserved and reluctant to participate in class to lose their inhibitions and emerge as valuable contributors to the group. One student, for example, stated:

Everyone is able to interact and become part of the lesson and also talk to people outside their circles.

Arts-based activities also affected teacher/learner relations. Students remarked that the process allowed them to experience me as less intimidating and more approachable. Many students requested that we engage in more classes with arts activities. My own observations were corroborated in the documented student feedback surveys and focus group interviews. The arts-based lessons were non-threatening, indirect and playful and participants felt safer expressing their views and engaging with me in the arts-based classroom. A participant confirmed, "When I am happy, I understand better."

Freire $(2000,2005)$ argues that the traditional transmission or "banking" methods tend to quash curiosity; this I interpreted as a stifling of the desire and motivation to learn in trust. This capacity is about a willingness to enter into a reciprocal teaching and learning relationship. When students experience negative feelings in the classroom-whether they are conscious of them or not - they tend to shut down or act out (Bozalek, Garraway, and McKenna 2011; Freire 2005; Mann 2008; Stone Hanley 2013). On the other hand, when motivated, students are open to giving and receiving and are therefore able to engage more fully. I observed earnest and joyful student participation and contributions in the arts-based lessons. One participant remarked, "I am inspired-I want to come to class now."

During these interventions, my role shifted to that of a facilitator and classes became more flexible and dynamic. Students were not confined to their desks and were able to arrange the room to suit their needs. I stepped away from the podium and moved freely among the students, resulting in more personalised teaching moments. 


\section{Beagle}

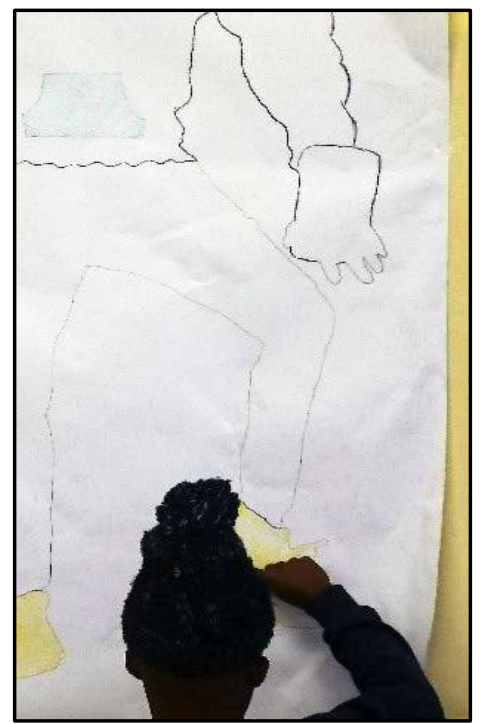

Figure 1: Non-verbal communication, Doornfontein Campus, 2018 (photograph by the author)

Even though I introduced the same arts-based brief to all my classes, each iteration played out differently, illustrating the horizontal co-creation and production of knowledge and demonstrating the generative nature of the methods. For example, one group combined their individual artworks to create a group image (Figure 2) and sang together while making it, while another used their artworks as props for a television show as a way to share. The arts-based methods facilitated student contributions and enabled greater student autonomy in shaping their classroom experiences. As one participant explained, "through art it is easier to express myself without having to explain verbally". 


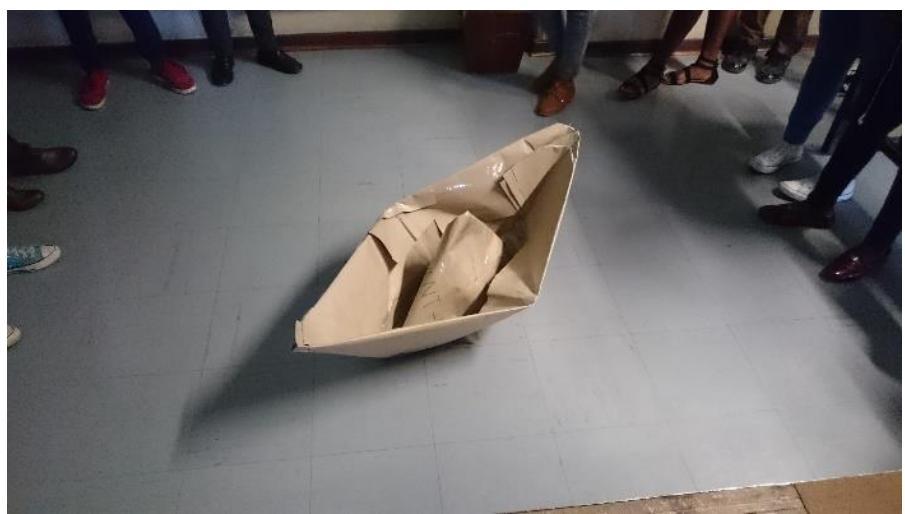

Figure 2: Group image: "Boat", Doornfontein Campus, 2017 (photograph by the author)

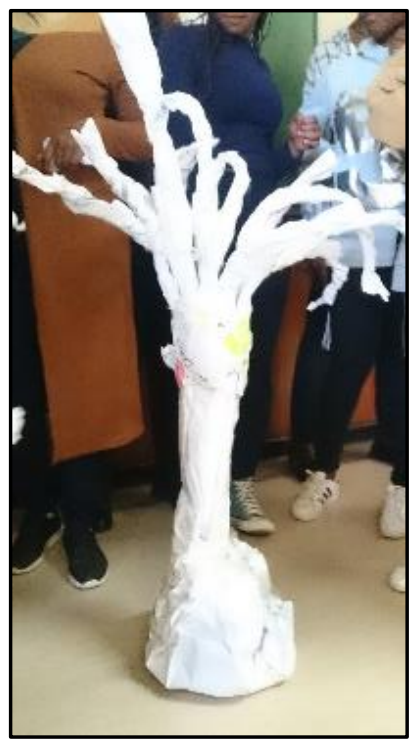

Figure 3: "Tree": free-standing sculpture, Auckland Park Bunting Road Campus, 2018 (photograph by author)

Eisner (2002) and many other authors (such as Dewey 1934; McNiff 2012; Newfield 2011) highlight the usefulness of the arts as a thinking and learning tool. Participants found it easier to access, think about and communicate their ideas as well as remember the relevant concepts. One participant revealed:

I can tell you that all those activities I remember them better and I remember everything clearly like more than if we only read about it. All those activities I still remember them clearly. 
This study found that by representing their knowledge through multiple modes students could assert their unique identities and express their ideas in ways that were more fluid and less rigid or limited. Students enjoyed greater autonomy in how they represented themselves and were able to exercise greater voice and visibility in the classroom. These capacities can also be extended to foster, for students, "a sense of authoring through multimodal production" (Thibaut and Scott Curwood 2018, 48). Remarks by two participants are worth noting here:

You are learning everyday peoples' views, you come to class; people have different views and it is like, wow I actually never thought of it that way. So, you get different perspectives which makes you aware of everything.

... you "see" others ... who usually you don't see.

Integrating culturally relevant arts-based methods recognises and gives expression to student capabilities that promote participation in the classroom. The participants in this study found the arts-based activities enjoyable and engaging and were therefore motivated to participate. Participants who identify as shy found the activities less stressful than more traditional modes of learning. Stone Hanley (2013) contends that in an arts-based paradigm (CRAE), the art-making process enables the distillation of personal voice. It provides a platform for voice and creative choice and instils feelings of agency and empowerment. The artworks produced are a symbol of this. As one participant observed,

So, like with the art, it is like we are reflecting our life and applying what you are teaching. Then the artwork it is like a symbol of that.

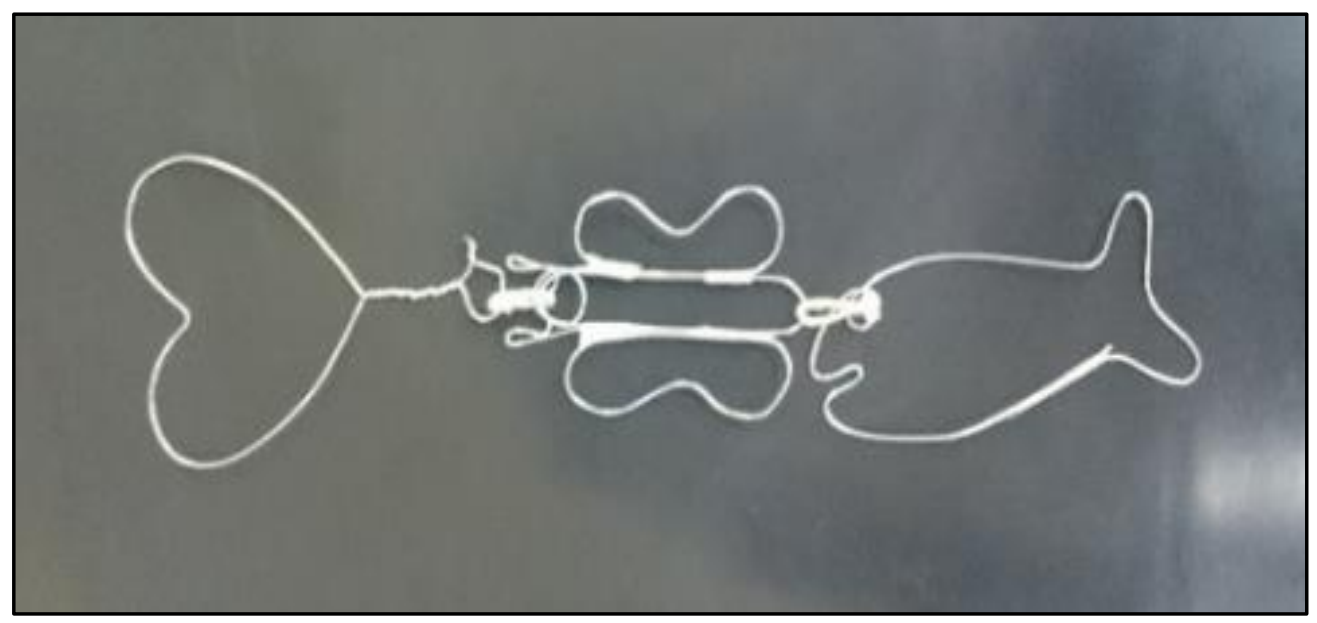

Figure 4: Body adornment: Protective amulet (from wire), Doornfontein Campus, 2017 (photograph by author) 
The artwork carries personal meaning and significance for the maker, as a participant revealed: "Can you believe I still have mine? I keep it next to my bed."

\section{Conclusion}

This study initiated an action research process that investigated how culturally relevant arts-based methods might be utilised to transform traditional classroom dynamics by making knowledge more accessible and reducing some of the constraints that students experience in the extended curriculum WPP programme.

My research findings from this project support the notion of access to multiple ways of knowing and demonstrate how culturally relevant arts-based methods embrace "other ways of knowing". Moreover, they notably impacted the curriculum by influencing and promoting a more democratic and equitable pedagogy. Arts-based methods offer opportunities to renegotiate pedagogic relationships and to embrace more egalitarian modes of teaching and learning. The arts-based approaches helped students to clarify their own ideas and assert their identities in a safe and non-judgmental environment. In addition, arts-based methods introduced a more flexible and less threatening way to teach and learn, which can be especially useful in a heterogeneous context. These methods helped to integrate WPP learning content and contribute to other aspects of relational dynamics, such as group cohesion and increased motivation.

Arts-based methods have transformative potential to reduce some of the challenges of the contemporary classroom. These methods are well suited to the self-reflective aspect of the soft skills programme promoted in the WPP module. Students' artworks can offer a powerful personal symbol that activates and mediates many intrapersonal and interpersonal processes and act as key agents for building more democratic and reciprocal experiences of learning and teaching in higher education.

The integration of culturally relevant arts processes into the WPP module has initiated processes that address the need for re-imagining pedagogies that are aligned with contemporary contexts and reflect the diversity of the classroom. At the same time, these approaches to curricula offer novel ways for educators to transform teaching practices in keeping with social justice agendas by opening the space for more human relationships in education. This approach also facilitates flexible modes of communication that both accommodate and affirm a diverse student cohort.

This study contributes to the development of a transformative curriculum that enables more empowering learning experiences in the Workplace Preparation module. The introduction of arts-based approaches to teaching and learning allows students to connect subjectively with the material being taught and to assert their individual perspectives as part of the learning process.

Ultimately, the study assesses, within the context of the University of Johannesburg's Academic Development Access Programme, the impact of introducing arts-based 
methods in supporting student access and integration in the context of the WPP learning environment. The findings support pedagogical transformation using principles of agency and empowerment as central features of student-centred learning.

\section{Acknowledgements}

I would like to acknowledge the students who participated in the study, my supervisors Kim Berman and Graham Dampier, and the Departments of Visual Art, Access, and Workplace Preparation at the University of Johannesburg, whose invaluable contributions and support made this study possible.

\section{References}

Andrew, D. 2011. "The Artist's Sensibility and Multimodality-Classrooms as Works of Art". $\mathrm{PhD}$ diss., University of the Witwatersrand. Accessed October 7, 2021. https://core.ac.uk/download/pdf/39670120.pdf.

Andrew, D. 2014. "An Aesthetic Language for Teaching and Learning: Multimodality and Contemporary Art Practice". In Multimodal Approaches to Research and Pedagogy: Recognition, Resources, and Access, edited by A. Archer and D. Newfield, 200-17. New York, NY: Routledge.

Archer, A. 2014. "Multimodal Designs for Learning in Contexts of Diversity". Designs for Learning 7 (2): 8-28. https://doi.org/10.2478/dfl-2014-0061.

Ballim, Y. 2018. "Ways of Knowing and the Possible Contributions of Curriculum to the Decolonising Project". Scholarship of Teaching and Learning in the South 2 (1): 136-44. https://doi.org/10.36615/sotls.v2i1.54.

Bawa, A. 2014. Foreword to Perspectives on Student Affairs in South Africa, edited by M. Speckman and M. Mandew, v-vii. Cape Town: African Minds.

Berman, K. 2014. "Arts for Social Change". In Arts Activism, Education, and Therapies: Transforming Communities across Africa, edited by H. Barnes, 3-15. New York, NY: Rodopi.

Berman, K. 2018. "Evaluation". In Changing Our Worlds: Art as Transformative Practice, edited by M. LeBaron and J. Sarra, 87-126. Stellenbosch: Sun Press.

Berman, K., and S. Netshia. 2018. "Enlivening Pedagogical Methods in the Classroom through Visual Arts". Scholarship of Teaching and Learning in the South 2 (1): 4-20. https://doi.org/10.36615/sotls.v2i1.26.

Bozalek, V., J. Garraway, and S. McKenna. 2011. Case Studies of Epistemological Access in Foundation / Extended Curriculum Programme Studies in South Africa. Cape Town: Pearson. Accessed October 7, 2021. https://www.cput.ac.za/files/images_folder/units/fundani/Epistemological.pdf. 
Calitz, T. 2015. “A Capabilities Approach to Student Experiences of Pedagogy, Power and Well-Being at a South African University". PhD diss., University of the Free State.

Charmaz, K. 2006. Constructing Grounded Theory: A Practical Guide through Qualitative Analysis. London: Sage Publications.

CHE (Council on Higher Education). 2015. “Annexure 6-Transformation in Higher Education". Discussion paper prepared for the second national Higher Education Transformation Summit, 2015. Accessed October 7, 2021. https://www.justice.gov.za/commissions/FeesHET/docs/2015-HESummitAnnexure06.pdf.

Crenshaw, K. 1994. "Mapping the Margins: Intersectionality, Identity Politics, and Violence against Women of Color". In The Public Nature of Private Violence, edited by M. Fineman and R. Mykitiuk, 93-118. New York, NY: Routledge.

Davies, R 1998. “An Evolutionary Approach to Facilitating Organisational Learning: An Experiment by the Christian Commission for Development in Bangladesh". Impact Assessment and Project Appraisal 16 (3): 243-50. https://doi.org/10.1080/14615517.1998.10590213.

Davies, R., and J. Dart. 2005. The "Most Significant Change” (MSC) Technique: A Guide to How to Use It. Accessed October 7, 2021. https://mande.co.uk/wpcontent/uploads/2018/01/MSCGuide.pdf.

Dewey, J. 1934. Art as Experience. New York, NY: Capricorn Books.

DHET (Department of Higher Education and Training). 2013. White Paper for Post-School Education and Training: Building an Expanded, Effective and Integrated Post-School System. Pretoria: DHET. Accessed October 6, 2021. https://www.dhet.gov.za/SiteAssets/Latest\%20News/White\%20paper\%20for\%20postschool\%20education $\% 20$ and $\% 20$ training.pdf.

DoE (Department of Education). 1997. Education White Paper 3-A Programme for the Transformation of Higher Education. DoE: Pretoria. Accessed October 7, 2021. http://www.che.ac.za/sites/default/files/publications/White_Paper3.pdf.

Du Plooy, L., and M. Zilindile. 2014. "Problematising the Concept Epistemological Access with Regard to Foundation Phase Education towards Quality Schooling". South African Journal of Childhood Education 4 (1): 187-201. https://doi.org/10.4102/sajce.v4i1.51.

Eisner, E. W. 2002. The Arts and the Creation of Mind. New Haven, CT: Yale University Press.

February, C. A. 2016. “Re-imagining 'Non-Traditional' Student Constructs in Higher Education: A Case Study of One South African University". PhD diss., University of the Western Cape. http://etd.uwc.ac.za/xmlui/handle/11394/5457. 
Freire, P. 2000. Pedagogy of the Heart. Translated by D. Macedo and A. Oliveira. New York, NY: Continuum.

Freire, P. 2005. Pedagogy of the Oppressed. London: Continuum.

Gravett, S. 2002. "Transformative Learning through Action Research: A Case Study from South Africa”. Paper presented at the Adult Education Research Conference. Accessed October 7, 2021. https://newprairiepress.org/aerc/2002/papers/22.

Hendricks, C., and B. Leibowitz. 2016. "Decolonising Universities Isn't an Easy Process-But It Has to Happen”. The Conversation, May 23, 2016. Accessed October 7, 2021. https://theconversation.com/decolonising-universities-isnt-an-easy-process-but-it-has-tohappen-59604.

King, A. 1993. "From Sage on the Stage to Guide on the Side". College Teaching 41 (1): 3035. https://doi.org/10.1080/87567555.1993.9926781.

Kress, G., C. Jewit, J. Ogborn, and C. Tsatsarelis. 2001. "Rhetorics of the Science Classroom: A Multimodal Approach". In Multimodal Teaching and Learning: The Rhetorics of the Science Classroom, by G. Kress, C. Jewit, J. Ogborn and C. Tsatsarelis, 10-42. New York, NY: Bloomsbury Publishing.

Liamputtong, P., and J. Rumbold. 2008. Knowing Differently: Arts-Based and Collaborative Research Methods. New York, NY: Nova Science Publishers.

Lotz-Sisitka, H. 2009. "Epistemological Access as an Open Question in Education”. Journal of Education 46: 57-79.

Manik, S. 2015. "Calibrating the Barometer: Student Access and Success in South African Public Higher Education Institutions”. Alternation 17: 226-44. Accessed October 8, 2021. http://alternation.ukzn.ac.za/Files/docs/Special\%20Editions/SP17.pdf\#page=230.

Mann, S. J. 2008. Study, Power and the University: The Institution and Its Effects on Learning. Maidenhead: McGraw-Hill Education.

McMahon, B. J., and J. P. Portelli, eds. 2014. Student Engagement in Urban Schools: Beyond Neoliberal Discourses. Charlotte, NC: Information Age Publishing.

McNiff, S. 2012. “Opportunities and Challenges in Art-Based Research”. Journal of Applied Arts and Health 3 (1): 5-12. https://doi.org/10.1386/jaah.3.1.5_1.

McNiff, J. 2013. Action Research: Principles and Practice. London: Routledge. https://doi.org/10.4324/9780203112755.

Mills, G. E. 2000. Action Research: A Guide for the Teacher Researcher. Upper Saddle River, NJ: Pearson Education. 
MoE (Ministry of Education). 2001. National Plan for Higher Education. Pretoria: MoE. Accessed October 6, 2021. https://www.justice.gov.za/commissions/feeshet/docs/2001NationalPlanForHigherEducation.pdf.

Morrow, W. 2007. Learning to Teach in South Africa. Cape Town: HSRC Press.

Newfield, D. 2011. "Multimodality and Children's Participation in Classrooms: Instances of Research". Perspectives in Education 29 (1): 27-35.

Patton, M. Q. 2011. Development Evaluation: Applying Complexity Concepts to Enhance Innovation and Use. New York, NY: The Guilford Press.

Rabiger, S. 1990. “Art Therapy as Container". In Working with Children in Art Therapy, edited by C. Case and T. Dalley, 23-38. London: Routledge.

Rusznyak, L., L. Dison, M. Moosa, and M. Poo. 2017. "Supporting the Academic Success of First-Year Students in South Africa: A Study of the Epistemological Access They Acquired through a Lecture and Text”. South African Journal of Higher Education 31 (1): 207-26. https://doi.org/10.20853/31-1-1026.

Sen, A. 2005. Development as Freedom. New York, NY: Anchor Books.

Shandler, M. 2014. "Collaborative Partnerships to Facilitate Change in Higher Education". Mediterranean Journal of Social Sciences 5 (3): 1533-540. https://doi.org/10.5901/mjss.2014.v5n23p1533.

Stein, P., and D. Newfield. 2007. "Multimodal Pedagogies, Representation and Identity: Perspectives from Post-Apartheid South Africa". In International Handbook of English Language Teaching, edited by J. Cummins and C. Davison, 919-30. Boston, MA: Springer.

Stone Hanley, M. 2013. "Culturally Relevant Arts Education for Social Justice”. In Culturally Relevant Arts Education for Social Justice: A Way Out of No Way, edited by M. Stone Hanley, G. W. Noblit, G. L. Sheppard and T. Barone, 1-10. New York, NY: Routledge. https://doi.org/10.4324/9780203077573.

Stone Hanley, M., G. W. Noblit, G. L. Sheppard, and T. Barone, eds. 2013. Culturally Relevant Arts Education for Social Justice: A Way Out of No Way. New York, NY: Routledge. https://doi.org/10.4324/9780203077573.

Thibaut, P., and J. Scott Curwood. 2018. "Multiliteracies in Practice: Integrating Multimodal Production across the Curriculum". Theory into Practice 57 (1): 48-55. https://doi.org/10.1080/00405841.2017.1392202. 


\section{Beagle}

Van Zyl, A. 2013. "Teaching the Students We Have: Two Perspectives on First Year Students at the University of Johannesburg and the UJ First Year Experience Initiative". In Proceedings of the Higher Education Learning and Teaching Association of Southern Africa (HELTASA) 2013 Conference, edited by N. Tisani and A. Hlengwa. Pretoria: HELTASA. Accessed October 7, 2021. http://heltasa.org.za/wpcontent/uploads/2014/09/HELTASA-2013-Teaching-the-Students.pdf.

Van Zyl, A., and E. De Kadt. 2017. "Growing an FYE Initiative for the Diverse Student Population at the University of Johannesburg". University of Johannesburg. Accessed October 7, 2021. https://sc.edu/nrc/presentation/international/2011/files/CI-16.pdf.

Walker, M. 2005. Higher Education Pedagogies. Maidenhead: McGraw-Hill Education.

Walker, M. 2010. "Critical Capability Pedagogies and University Education”. Educational Philosophy and Theory 42 (8): 898-917. https://doi.org/10.1111/j.1469-

5812.2007.00379.x.

Walker, M., and E. Unterhalter, eds. 2007. Amartya Sen's Capability Approach and Social Justice in Education. New York, NY: Palgrave Macmillan. https://doi.org/10.1057/9780230604810.

YW Boston. 2017. "What Is Intersectionality, and What Does It Have to Do with Me?" YW Boston (blog), March 29, 2017. Accessed October 7, 2021. https://www.ywboston.org/2017/03/what-is-intersectionality-and-what-does-it-have-to-dowith-me/. 